\title{
Diversity of yeast strains isolated from the "magnan" a traditional ferment used for the production of "attiéké" a cassava food in Côte d'Ivoire
}

\author{
Modeste Kouadio Konan, Antoine Allah Assamoi, Karou Tago Germain \\ University of Félix Houphouët-Boigny, Faculty of Biosciences, Biotechnology Laboratory, Abidjan, Côte d'Ivoire, 22 \\ PO 582 Abidjan, \\ Corresponding author Tel: +22577774878; Email: konan.modeste.mk@gmail.com
}

Original submitted in on $18^{\text {th }}$ January 2019. Published online at www.m.elewa.org/journals/ on $30^{\text {th }}$ April 2019 https://dx.doi.org/10.4314/jab.v136i1.2

\begin{abstract}
Objective: This study aimed to identify the yeasts in the traditional fermented cassava root called "magnan", used for fermentation of cassava dough for "attiéké: a fermented cassava food product" production in Côte d'Ivoire.

Methodology and results: "magnan" is a fermented cassava root used as a traditional starter and "attiéké" is a fermented cassava food product. This study involved 99 samples of "magnan" taken from different production areas in eleven (11) communes in the District of Abidjan (Abobo, Adjamé, Anyama, Attécoubé, Bingerville, Cocody, Koumassi, Marcory, Port-Bouët, Songon and Yopougon). Samples of "magnan" were collected and carried to the Biotechnology Laboratory of the Félix Houphouët-Boigny University, during sixmonth (May - November 2017) and treated separately on MYPG medium (malt extract, yeast extract, peptone, glucose, and chloramphenicol). One hundred and six (106) pure yeast cultures were identified at genus and species level by MALDI-TOF mass spectrometry at the bio-bank laboratory of the Pasteur Institute of Côte d'Ivoire. A total of 83 yeast isolates were clearly identified $(78.30 \%)$ and showed five genus: Candida, Saccharomyces, Trichosporon, Kloeckera, and Millerozyma. The major species included C. krusei $(30.12 \%)$, C. tropicalis $(28.92 \%)$, and S. cerevisiae $(20.50 \%)$ followed by a low proportion of $C$. kefyr (6.02 \%), C. guilliermondii (3.61 \%), T. asahii (3.61\%), K. apis (2.41\%), C. pararugosa (1.20\%), M. farinosa (1.20\%) and C. albicans (1.20\%).

Conclusion and application of the results: This study showed the traditional cassava ferment "magnan" used for the fermentation of cassava dough for the production of "attiéke " on the sampled sites was colonized by several yeasts genera including Candida, Saccharomyces, Trichosporon, Kloeckera and Millerozyma in varying proportions. The frequently isolated species were composed by C. krusei, C. tropicalis and $S$. cerevisiae. The results obtained will constitute a database on the diversity of yeasts for the selection of starter strains for producing of "attiéké ". In perspective, the techno-functional properties (enzyme production: amylase, cellulase, pectinase, phytase, tannase and $\beta$-glucosidase) of each strain will be determined for their impact on the fermenting process of the cassava dough. And the starter strains will be used by producers to optimize and standardize the quality of "attiéké ".
\end{abstract}

Keywords: yeast strains, traditional ferment, "attiéké ", "magnan" 


\section{INTRODUCTION}

"attiéké " is a fermented cassava semolina cooked with steam from water which has a slightly acidic taste. It is a food that is much appreciated by many people in Côte d'Ivoire, in the West African sub region and elsewhere in the world (Europe, USA) where it is exported through the Africans in diaspora (Bouatenin et al., 2016; Assanvo et al., 2006). "attiéké " has now become a profitable dish, produced on a large scale because of the ever-increasing demand and then, its commercialization generates enough gain for both producers and the Ivorian economy (Krabi, 2016). In Côte d'Ivoire, "attiéké " is mainly produced by housewives and has several types depending on the main ethnic groups producing it. According to Assanvo et al. (2000), Djeni et al. (2015), there are in Côte d'Ivoire: "attiéké Ebrié", "attiéké Adjoukrou", "attiéké Alladjan" and "attiéké Avikam". However, despite its popularity, the preparation of "attiéké " remains informal and is based on empirical knowledge passed down from generation to generation. Its production requires a preliminary and essential stage of fermentation of the cassava dough from a traditional cassava inoculum commonly called "magnan" which is obtained naturally after 2-3 days of spontaneous fermentation of cassava roots (about 1/10 of the dough to ferment) previously boiled or braised. Therefore, regardless of the type of "attiéké " resulting from the fermentation of the cassava dough, there is a great variability with the final organoleptic quality in the same producer or from one producer to another even of an ethnic group to another (Djeni et al., 2008). This fluctuation in the quality, can probably be attributed to the variability of the involved fermentative germs (Oyewole and Sanni, 1995 ). Thus, it would be wise to effectively control the fermentation process which is a very decisive step in obtaining quality products. This

\section{MATERIAL AND METHODS}

Collection of samples: Sampling was carried out in eleven (11) municipalities in the District of Abidjan (Abobo, Adjamé, Anyama, Attécoubé, Bingerville, Cocody, Koumassi, Marcory, Port-Bouet, Songon and Yopougon) (Figure 1). The criteria for choosing these control necessarily implies a precise identification of the fermentative germs implicated. According to previous work, it has been reported that the major microorganisms of the fermentation of " magnan " for the production of "attiéké " consisted of yeasts, lactic acid bacteria, and Bacillus (Assanvo et al., 2006). However, there is insufficient data on yeast and its diversity in this fermentative process for the production of "attiéké " for comparisons, despite the fact that yeast is a major microorganism in the production of an "attiéké " of good organoleptic quality. In Africa, Asia and Brazil, yeast(s) have been reported to play an important role in the fermentation of cassava-based foods such as: "tapioka, lafun and fufu...", several yeast species have been isolated from these fermented products (Schwan et al., 2007). For the production of "fufu", for example, six different yeast species, Pichia saitoi, Pichia anomala, Candida krusei, Candida tropicalis, Zygosaccharomyces bailii and Saccharomyces cerevisiae have been identified (Oyewole, 2001). In the case of "attiéké ", only the species of C. tropicalis, C. krusei and S. cerevisiae have been identified (Coulin et al., 2006). Thus, information on the yeast diversity of "magnan" could be an important database for the selection of the best starter-type strains for the production of "attiéké". The aim of this work is therefore to isolate and identify the different yeast species involved in the fermentation of the "magnan" for the production of "attiéké " in Côte d'lvoire, especially in eleven municipalities of the District of Abidjan (Abobo, Adjamé, Anyama, Attécoubé, Bingerville, Cocody, Koumassi, Marcory, PortBouet, Songon and Yopougon). The choice of these municipalities was related to their importance in the production and marketing of attiéké in Côte d'Ivoire.

municipalities was defined in the introduction (Krabi, 2016). In each of these municipalities, three major producers were randomly selected. At each of them, three pieces of boiled and fermented cassava were taken with a stainless steel spoon and placed in sterile 
Stomacher bags, and introduced in a cooler and taken to the laboratory for yeasts isolation. Sampling took place over a six-month period between May and November 2017.

Isolation, purification and storage of yeasts: Once at the laboratory, the samples were treated separately by municipality. The surfaces of the traditional "magnan" ferments were scraped with a spatula and mixed, then divided into three aliquots from which the stock solutions were prepared. For the preparation of the stock solutions, $10 \mathrm{~g}$ of each aliquot were homogenized in $90 \mathrm{~mL}$ of buffered peptone water (EPT,
AES Laboratory, France) and incubated at $30^{\circ} \mathrm{C}$ for 18 hours to revitalize the microorganisms of the traditional ferment. After incubation, MYPG agars with $100 \mathrm{mg} / \mathrm{L}$ chloramphenicol (chloramphenicol was used to inhibit the growth of bacterial flora) were seeded by striae and incubated at $30^{\circ} \mathrm{C}$ for 48 hours. Colonies identified as yeasts by their macroscopic aspects on agar medium and their microscopic observations in the fresh state were purified by striae on MYPG agar. One hundred and six (106) purified isolates were obtained and stored at $\left(-80^{\circ} \mathrm{C}\right)$ in MYPG broth with $20 \%(\mathrm{v} / \mathrm{v})$ of glycerol added (Nielsen et al., 2005).

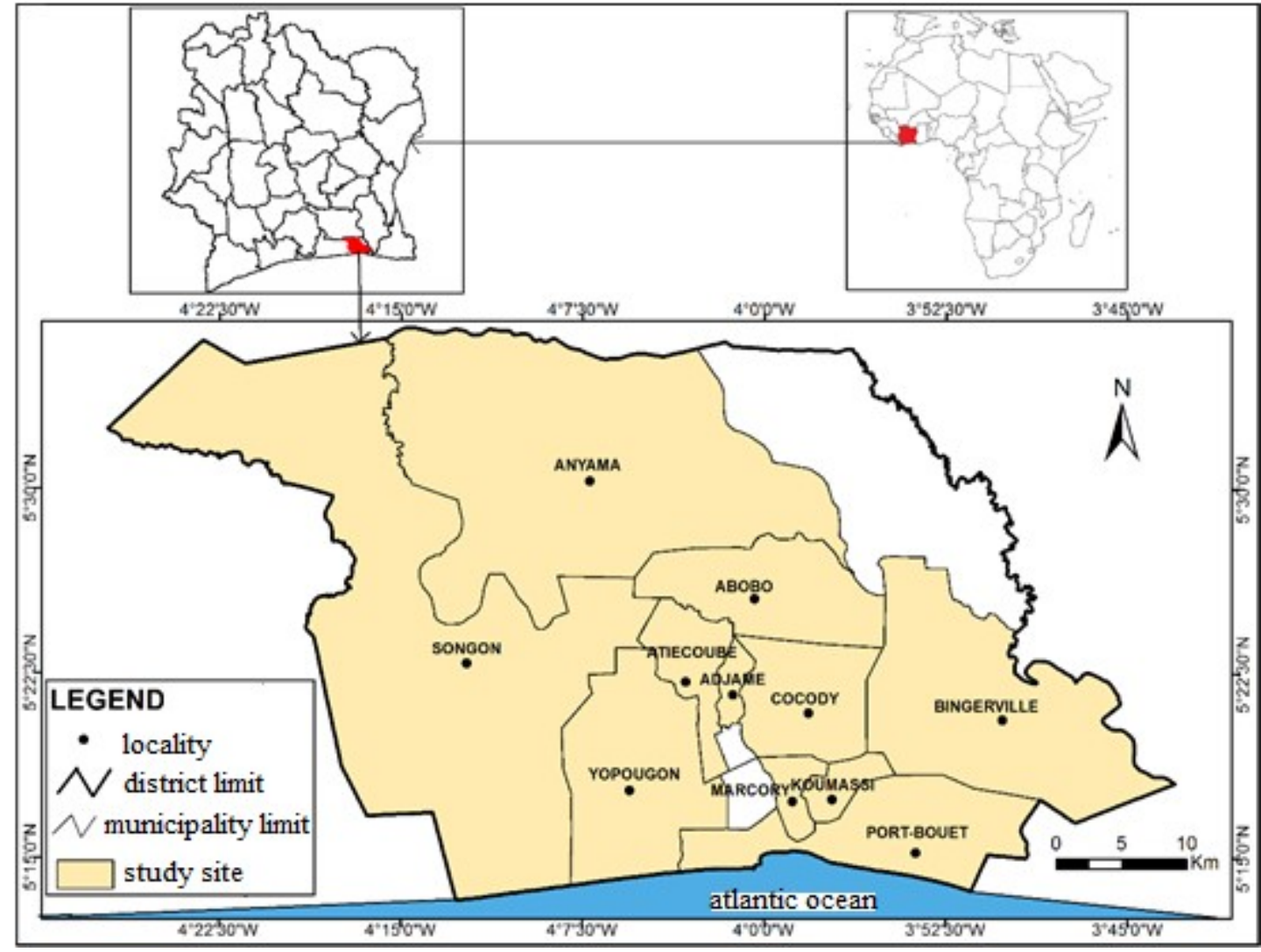

Figure 1: Sampling areas of the "magan" in Abidjan district

Identification of yeasts by MALDI-TOF mass spectrometry: The identification of yeasts at the genus and species level by borrowing mass of ribosomal proteins was done by the MALDI-TOF (Vitek MS BioMerieux) mass spectrometer, which is a spectrometer using a matrix-assisted laser ionization source $\quad(M A L D I=$ Matrix-Assisted Laser Desorption/lonization) and a time-of-flight analyzer (TOF = Time-Of-Flight). The separation of molecules by this technique is softer than with other methods. It allows the ionization of large, low-volatility and heat- sensitive molecules without degrading them. MALDITOF identification is done in three steps: sample preparation followed by sample analysis and data processing (Karas et al., 1985). For samples preparation, the 106 strains of yeasts isolated from the cassava ferment "magnan" were cultured in MYPG agar medium for 48 hours at $30^{\circ} \mathrm{C}$. Afterwards, a colony of the calibrating strain, Escherichia coli ATCC 8739 , was put on the MALDI-TOF plate with $1 \mu \mathrm{L}$ of CHCA matrix (acid a-cyano-4-hydroxycinnamic, BioMerieux SA, ref 411071). Then, using a sterile oese 
calibrated at $1 \mu \mathrm{L}$, a colony of yeast to be tested was collected and put on the target wells. The sample was tested in duplicate. On both deposits, $0.5 \mu \mathrm{L}$ of $25 \%$ formic acid (vitek MS-FA, BioMerieux SA, ref 411072) was added. After air drying, $1 \mu \mathrm{L}$ of CHCA matrix was put on each spot and dried again. Subsequently, the deposition plate was introduced into the Vitek MS for sample analysis after transferring the data from the Prep Station, which is a module consisting of a computer and an optical scanner used to introduce the sample data and their location on the slide to the Vitek MS. Once in the device, the target or sample to be tested was subjected to laser beams to allow the matrix to be vaporized and the molecules in the sample to be ionized. The ionized molecules thus formed migrate to the detector and were separated according to their

\section{RESULTS}

Identification by MALDI-TOF mass spectrometry allowed a formal identification of 83 strains out of the 106 strains submitted for the analysis with confidence degree of $99.9 \%$. This represented an identification rate of $78.30 \%$ against a lack of identification of 23 charge and molecular weight. Then the detector sends the recorded information to the analyzer for the data processing in the form of a spectrum where each peak corresponds to a type of molecule. And the device integrates the peaks recorded in comparison with the database to search for the identification of the corresponding germ. The interpretation of the results involved two important parameters: the percentage confidence degree and the confidence level displayed by different colours. First, a confidence degree between 99.9 and $60 \%$ with a green colour indicates good identification and second, a confidence degree of less than $60 \%$ with an orange coloration corresponds to a low probability of identification. And an absence of identification is manifested by non-percentage with a red coloration.

strains with a rate of $21.70 \%$. Figure 2 shows an example of a ribosomal mass borrowing profile using MALDI-TOF mass spectrometry of a Saccharomyces cerevisiae species.

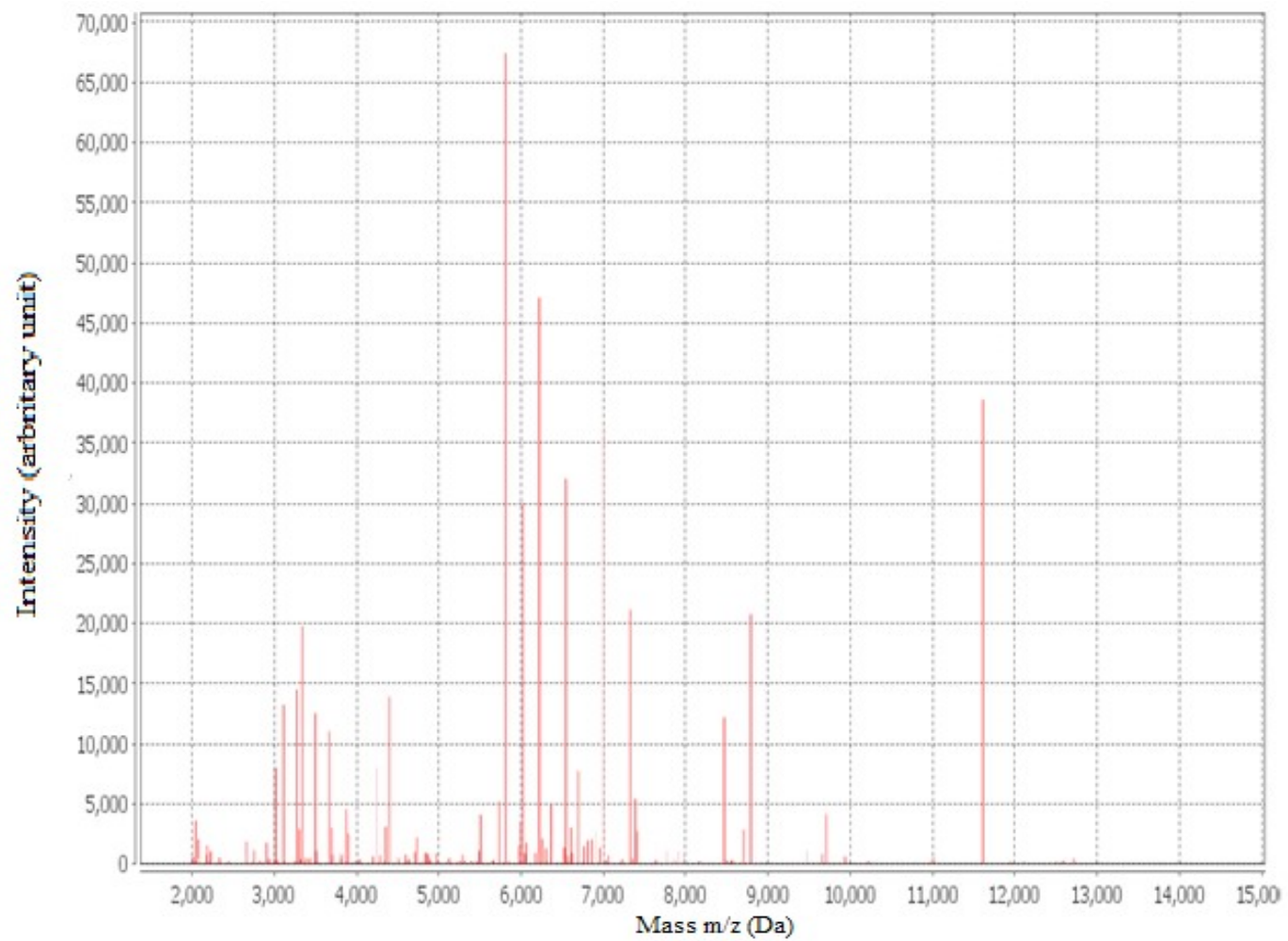

Figure 2: Ribosomal mass borrowing profile of a strain of Saccharomyces cerevisiae

Identification revealed five (5) genus and eleven (11) species which are: Candida krusei (30.12\%), Candida tropicalis (28.92\%), Candida kefyr (6.02\%), Candida guilliermondii (3.61\%), Candida pararugosa (1.20 \%), 
Konan et al., J. Appl. Biosci. 2019 Diversity of yeast strains isolated from the "magnan" a traditional ferment used for the production of "attiéké" a cassava food in Côte d'Ivoire

Candida pelliculosa (1.20\%), Candida albicans (1.20 asahii (3.61\%), Kloeckera apis (1.23\%), Millerozyma $\%)$, Saccharomyces cerevisiae (20.50\%), Trichosporon farinosa $(2.40 \%)$, (Table 1).

Table 1: Yeasts species identified by MALDI-TOF mass spectrometry

\begin{tabular}{l|l|l|l|l}
\hline Genus & Species & Numbers & Percentage (\%) & Score \\
\hline & C. albicans & 1 & 1.20 & 99.9 \\
& C. guilliermondii & 3 & 3.61 & 99.9 \\
Candida & C. kefyr & 5 & 6.02 & 99.9 \\
& C. krusei & 25 & 30.12 & 99.9 \\
& C. pararugosa & 1 & 1.20 & 99.9 \\
& C. pelliculosa & 1 & 1.20 & 99.9 \\
Kloeckera & C. tropicalis & 24 & 28.93 & 99.9 \\
Millerozyma & K. apis & 2 & 2.41 & 99.9 \\
Saccharomyces & M. farinosa & 1 & 1.20 & 99.9 \\
Trichosporon & S. cerevisiae & 17 & 20.50 & 99.9 \\
\hline Total & T. asahii & 3 & 3.61 & 99.9 \\
\hline
\end{tabular}

\section{DISCUSSION}

This study results showed that the traditional cassava ferment "magnan" used for fermentation of cassava dough for "attiéké " production was colonized by a variety of fermentative and pathogenic yeasts, such as Candida albicans. This variability of species could be explained by the lack of hygiene in which traditional fermentations took place. The identification showed that the predominant genera are Candida $(72.28 \%)$ and Saccharomyces $(20.50 \%)$ followed by a small proportion of the species Trichosporon asahii $(3 \%)$, Kloeckera apis $(2.41 \%)$ and Millerozyma farinosa (1.20 $\%)$. With Candida, the majority of species were $C$. krusei $(30.12 \%)$ and C. tropicalis (28.92\%). These results were in agreement with those of Coulin et al. (2006), who identified in the case of "attiéké " the strains of $C$. tropicalis, C. krusei and S. cerevisiae. Also, the studies of Assanvo et al. (2006) indicated that yeasts (Candida sp.: 68\%, C. valida : 9\%, C. homii : $7 \%$, C. krusei : $2 \%$, Kloeckera japonica : $7 \%$ and Saccharomyces cerevisiae : 7\%) constituted a significant part of the dominant microflora of traditional cassava starters "Adjoukrou" in the three sampled villages. In fact, during the submerged fermentation of cassava, only yeasts and lactic acid bacteria survive under the strong acidic conditions of the fermentation

\section{CONCLUSION}

At the end of this study, it appears that the traditional cassava ferment "magnan" used for the fermentation of cassava dough used to make "attiéké " in Côte d'Ivoire, particularly in the Abidjan district, was colonized by yeasts of the genera Candida, Saccharomyces, medium (Oboh and Akindahunsi, 2003). According to Padonou et al. (2009), yeasts grow with lactic acid bacteria from beginning to end in fermented cassava dough used to produce the "lafun". In addition, some yeasts, including Saccharomyces cerevisiae, Zygosaccharomyces, Candida, Pichia, Kloeckera, Kluyveromyces, Endomycopsis, Lipomyces, etc. are known for their ability to synthesize enzymes such as: amylase, cellulase, pectinase and even the $\beta$ glucosidase (Blanco et al., 1999; Hasper et al., 2002; Tansel and Cengiz, 2013). Thus, considering the rigidity of the tissue of cassava and its toxicity, we could say that our strains isolated from the traditional ferment "magnan" would probably contribute to the softening of cassava and its detoxification in order to provide "attiéké " with a smooth and soft texture and a pleasant taste sought by consumers as demonstrated by Obilie et al. (2003) in Ghana as part of the Ghanaian "attiéké ". However, this preliminary study, which consisted in identifying the yeast species present in the "magnan", is more objective and will later aim to characterize the techno-functional properties of each of the isolated strains except the pathogenic ones in order to formulate yeast starters for the fermentation of cassava dough.

Trichosporon, Kloeckera and Millerozyma. C. krusei, C. tropicalis and $S$. cerevisiae were the major species. The results of this study will provide an important database on the diversity of "magnan" yeasts for the purpose of selecting better starter yeast strains for the production 
of an "attiéké " of good quality. In perspective, it will be necessary to evaluate the capacity of each strain to participate or not in the fermentation process of

\section{ACKNOWLEDGEMENTS}

We would like to thank the managers and staff of the Pasteur Institute of Côte d'Ivoire, in particular those of

\section{REFERENCES}

Assanvo JB, Agbo GN, Behi YEN, Coulin P, Farah Z, 2006. Microflora of traditional starter made from cassava for attiéké production in Dabou (Côte d'Ivoire). Food control, 17: 37-41.

Assanvo JB, Agbo NG, Behi N, Farah Z, 2000. Enquêtes de consommation et de production d'attiéké realisées à Abidjan, Dabou et à Jacqueville. Rapport LABSA Université de Cocody, Côte d'Ivoire)/CSRS/ETHZ, 6p.

Blanco P, Carmen S, Tomaès GV, 1999. Production of pectic enzymes in yeasts. Federation of European Microbiological Societies Letters 175: $1-9$

Bouatenin KMJP, Djéni NT, Kakou AC, Menan EHMD, 2016. Optimisation de la production de l' aamylase par les microorganismes isolés des ferments traditionnels de manioc provenant de trois zones de production de l'attiéké en Côte d'Ivoire. European Scientific Journal, 12: 259272.

Coulin P, Farah Z, Assanvo J, Spillmann H, Puhan Z, 2006. Characterisation of the microflora of attiéké, a fermented cassava product, during traditional small-scale preparation. International Journal of Food Microbiology, 106: 131-136.

Djeni NT, Bouatenin KMJP, Assohoun NMC, Toka DM, Menan EH, Dousset X, Dje KM, 2015. Biochemical and microbial characterization of cassava inocula from the three main attieke production zones in Côte d'lvoire. Food Control, 50: 133-140.

Djeni NT, N'guessan KF, Dadie AT, Dje KM, 2008. Impact of different rates of a traditional starter on biochemical and microbiological changes during the fermentation of cassava for attieke production. Food, 2: 145-151.

Hasper AA, Dekkers E, Mil MV, Van de Vondervoort PJI, De Graaff LH, 2002. Egl C, a new endoglucanase from Aspergillus niger with major activity towards xyloglucan. Applied and Environmental Microbiology, 68: 1556-1560. cassava dough in order to provide producer groups in the attiéké with efficient strains for the production of an attiéké of improved quality appreciated by consumers.

Adiopodoumé bio-bank laboratory, for their availability and support in the successful completion of this study.

Karas M, Bachmann D, Hillenkamp FAC, 1985. " Influence of the Wavelength in High-Irradiance Ultraviolet Laser Desorption Mass Spectrometry of Organic Molecules ". Analytical Chemistry, 57: 2935-2939.

Krabi ER, 2016. Sélection de starters de bacteries lactiques pour le contrôle de la fermentation de la pâte de manioc (manihot esculenta): Application biotechnologique pour la production d'attiéké. Thèse de doctorat, Université Félix Houphouët-Boigny, Côte d'Ivoire, $248 \mathrm{p}$.

Nielsen DS, Hønholt S, Debrah T, Jespersen L, 2005. Yeast populations associated with Ghanaian cocoa fermentations analysed using denaturing gradient gel electrophoresis (DGGE). Yeast, 22: 271-284.

Obilie EM, Debrah KT, Amoa-Awua WK, 2003. Microbial modification of the texture of grated cassava during fermentation into akyake. International Journal of Food Microbiology, 4: 259-273.

Oboh G, Akindahunsi AA, 2003. Chemical Changes in Cassava Peels Fermented with Mixed Culture of Aspergillus niger and Two species of Lactobacillus Integrated Bio-system. Applied Tropical Agriculture, 8: 63-68.

Oyewole OB, 2001. Characteristics and significance of yeasts involvement in cassava fermentation for fufu production. International Journal of Food Microbiology, 65: 213-218.

Oyewole OB, Sanni LO, 1995 Constraints in traditional cassava processing. In T. Agbor-Egbe, A. Brauman, D. Griffon, \& S. Treche (Eds.), Transformation Alimentaire Du Manioc.: Paris: Orstom, pp. 523-529.

Padonou SW, Dennis SN, Joseph DH, Line T, Mathurin $\mathrm{CN}$, Jakobsen M, 2009. The microbiota of Lafun, an African traditional cassava food product. International Journal of Food Microbiology, 133: 22-30. 
Schwan RF, Almeida EG, Souza-Dias MAG, Jespersen

$L$, 2007. Yeast diversity in rice-cassava fermentations produced by the indigenous Tapirapé people of Brazil. Federation of European Microbiological Societies, 7: 966972.

Tansel YH, Cengiz Ç, 2013. Isolation and Characterization of Amylase Producing Yeasts and Improvement of Amylase Production. Turkish Journal of Biochemistry, 38: 101-108. 